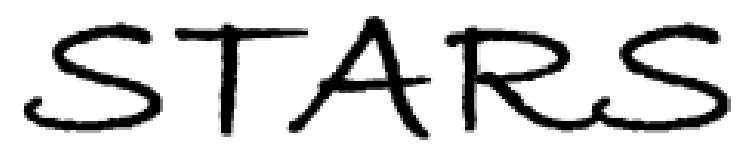

University of Central Florida

STARS

$1-1-2009$

\title{
Habitat-specific breeder survival of Florida Scrub-Jays: inferences from multistate models
}

David R. Breininger

University of Central Florida

James D. Nichols

Geoffrey M. Carter

Donna M. Oddy

Find similar works at: https://stars.library.ucf.edu/facultybib2000

University of Central Florida Libraries http://library.ucf.edu

This Article is brought to you for free and open access by the Faculty Bibliography at STARS. It has been accepted for inclusion in Faculty Bibliography 2000 s by an authorized administrator of STARS. For more information, please contact STARS@ucf.edu.

\section{Recommended Citation}

Breininger, David R.; Nichols, James D.; Carter, Geoffrey M.; and Oddy, Donna M., "Habitat-specific breeder survival of Florida Scrub-Jays: inferences from multistate models" (2009). Faculty Bibliography 2000 s. 7048.

https://stars.library.ucf.edu/facultybib2000/7048

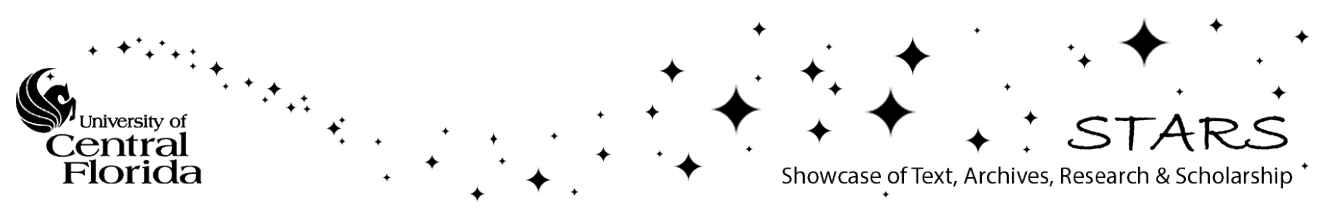




\title{
Habitat-specific breeder survival of Florida Scrub-Jays: inferences from multistate models
}

\author{
David R. Breininger, ${ }^{1,2,4}$ James D. Nichols,${ }^{3}$ Geoffrey M. Carter,${ }^{1}$ and Donna M. Oddy ${ }^{1}$ \\ ${ }^{1}$ Dyn-2, Dynamac Corporation, Kennedy Space Center, Florida 32899 USA \\ ${ }^{2}$ Department of Biology, University of Central Florida, 4000 Central Florida Boulevard, Orlando, Florida 32816 USA \\ ${ }^{3}$ United States Geological Survey, Patuxent Wildlife Research Center, Laurel, Maryland 20708 USA
}

\begin{abstract}
Quantifying habitat-specific survival and changes in habitat quality within disturbance-prone habitats is critical for understanding population dynamics and variation in fitness, and for managing degraded ecosystems. We used 18 years of color-banding data and multistate capture-recapture models to test whether habitat quality within territories influences survival and detection probability of breeding Florida Scrub-Jays (Aphelocoma coerulescens) and to estimate bird transition probabilities from one territory quality state to another. Our study sites were along central Florida's Atlantic coast and included two of the four largest metapopulations within the species range. We developed Markov models for habitat transitions and compared these to bird transition probabilities. Florida Scrub-Jay detection probabilities ranged from 0.88 in the tall territory state to 0.99 in the optimal state; detection probabilities were intermediate in the short state. Transition probabilities were similar for birds and habitat in grid cells mapped independently of birds. Thus, bird transitions resulted primarily from habitat transitions between states over time and not from bird movement. Survival ranged from 0.71 in the short state to 0.82 in the optimal state, with tall states being intermediate. We conclude that average Florida Scrub-Jay survival will remain at levels that lead to continued population declines because most current habitat quality is only marginally suitable across most of the species range. Improvements in habitat are likely to be slow and difficult because tall states are resistant to change and the optimal state represents an intermediate transitional stage. The multistate modeling approach to quantifying survival and habitat transition probabilities is useful for quantifying habitat transition probabilities and comparing them to bird transition probabilities to test for habitat selection in dynamic environments.
\end{abstract}

Key words: Aphelocoma coerulescens; capture-recapture; disturbance; fire; Florida Scrub-Jay; multistate models; patch dynamics; restoration; scrub; survival.

\section{INTRODUCTION}

Habitat-specific survival is critical for understanding many ecological relationships (Van Horne 1983, Pulliam 1988, Armstrong 2004), but is rarely estimated in ways that account for the potentially confounding effects of detection probabilities (Conroy 1993, Conroy et al. 1996, Diffendorfer 1998, Anders and Marshall 2005). Estimating habitat-specific survival becomes even more difficult when habitat transitions between states over time.

Habitat-specific demography is especially important in the face of changes in habitat, as both individual fitness and population dynamics are expected to change when habitat transitions between states over time. Patchy, successional habitats can be characterized at any point in time by a mosaic of successional states. For example, the rate of succession and the frequency of habitat disturbance are important determinants of metapopulation

Manuscript received 12 June 2008; revised 4 December 2008; accepted 4 February 2009. Corresponding Editor: J. R. Sauer.

${ }^{4}$ E-mail: david.r.breininger@nasa.gov dynamics for species that prefer early successional or transitional habitat states (Amarasekare and Possingham 2001, Ellner and Fussmann 2003). Management of species is strongly dependent on the nature of the successional process, the manner in which this process can be influenced by management, and the responses of species vital rates to the different habitats (e.g., F. A. Johnson, D. R. Breininger, B. W. Duncan, B. K. Williams, and M. C. Runge, unpublished manuscript).

Florida Scrub-Jays prefer transitional habitat states and exhibit greatest fitness in an intermediate successional state (Breininger and Carter 2003, Breininger and Oddy 2004). Florida Scrub-Jays are good candidates for habitat-specific survival studies because they rigorously defend territories year-round, which provide all necessary life requisites (Woolfenden and Fitzpatrick 1984). Florida Scrub-Jays are cooperative breeders that usually disperse once to breed within two kilometers from where they hatched (Woolfenden and Fitzpatrick 1984, Breininger et al. 2006). Habitat quality, demography, and dispersal have been characterized at the scale of Florida Scrub-Jay territories to describe how habitat features 
influence demographic success, but no published studies have applied modern mark recapture techniques (Mumme et al. 2000, Breininger and Carter 2003, Breininger and Oddy 2004). Here we used multistate capture-recapture models to test whether habitat quality within territories influences survival and detection probability and to estimate bird transition probabilities between territory quality states. We also developed Markov models using grid cells the size of average territories to estimate how birds would passively transition between habitat states. Passive transitions occur not because of bird movement, but because habitat in a bird's territory changes state. The ratio of bird transition probabilities from one territory quality state to another to these passive habitat transition probabilities provides a metric reflecting the degree of habitat selection. Testing a priori hypotheses about habitat-specific survival and transition probabilities will provide insights into habitat-specific variation in fitness, habitat-specific population dynamics, and management of metapopulations inhabiting successional habitat mosaics.

\section{Predictions}

We characterized habitat using four territory quality states that depend on the time since the last fire and its extent (short, optimal, tall mix, tall; Breininger and Carter 2003, Breininger and Oddy 2004). These territory quality states do not refer to vegetation composition but instead to habitat structure that influences Florida Scrub-Jay reproductive success. Florida Scrub-Jays defend larger territories than necessary to meet immediate life requisites, probably as an evolutionary response to frequent fire regimes and the necessity to have some habitat in optimal condition (Woolfenden and Fitzpatrick 1984). The optimal state not only has open sandy areas that persist for a few years after fire and are used for caching acorns and hunting prey, but also medium-height oaks $(1.2-1.7 \mathrm{~m})$ that are $3-20$ years post-fire and provide acorn production, nesting cover, and predator-escape cover. The optimal state lacks tall scrub, which is suboptimal because it reduces the ability to detect predators. Tall scrub is unburned for $>20$ years and usually results from fire suppression and habitat fragmentation that prevents fires from burning across landscapes (Duncan and Schmalzer 2004, Breininger et al. 2006).

We predicted that detection probabilities do not vary with sex, but decrease with increasing vegetation height in the following order of territory quality states: short, optimal, tall mix, tall. Florida Scrub-Jay family members usually stay close together, and all family members usually fly to investigators for peanut bits when investigators enter Florida Scrub-Jay territories (Woolfenden and Fitzpatrick 1984). Peanut bits were used to lure Florida Scrub-Jays into traps for initial banding and then to briefly attract family members to the observers so that their unique color-band sequences can be recorded. Florida Scrub-Jays are vulnerable to aerial predators (e.g., Cooper's Hawk, Accipiter cooperii) and are wary in tall, dense habitat where accipiters are difficult to detect (Breininger et al. 1996). Previous Florida Scrub-Jay studies did not account for detection probabilities and could have underestimated survival and improperly ordered the quality of territory quality states (e.g., Williams et al. 2002, MacKenzie et al. 2006).

Florida Scrub-Jays tend to remain in the same territories, and breeding dispersal is relatively rare (Woolfenden and Fitzpatrick 1984). There are two mechanisms that produce bird territory quality transitions. First, birds may actually shift territories to different locations, as jays may select certain habitat patches by slight adjustments in territory boundaries (e.g., Breininger and Carter 2003). Second, habitat at a territory location may change via disturbance (e.g., fire) or succession. Because of the site fidelity of Florida Scrub-Jays, we predicted that most territory quality transitions will be associated with habitat structural changes at a territory location rather than bird movement. However, in situations where movement and active habitat selection are involved, we predicted higher probabilities of movement to habitat states conferring higher fitness and lower probabilities of movement to states with reduced fitness.

We also predicted that breeder survival rates are nearly the same between sexes (Woolfenden and Fitzpatrick 1984, Breininger et al. 1996) and are consistently high for breeding birds, except during rare die-offs associated with mosquito-borne arbovirus outbreaks (Woolfenden and Fitzpatrick 1984, Breininger 1999, Garvin et al. 2004). Life history parameters that most influence population growth and fitness usually vary little with environmental conditions (Gaillard et al. 1998, Pfister 1998). We predicted that habitat-specific survival is ordered, from highest to lowest, as follows: optimal, tall mix, tall, and short (Breininger and Carter 2003, Breininger et al. 2006).

\section{Methods \\ Study areas}

Our study areas included 20 existing and proposed conservation areas along central Florida's Atlantic coast (Fig. 1; Breininger and Carter 2003, Breininger et al. 2006). These are remnants of an ecosystem that is fragmented by urban areas and that has become marginal for Florida Scrub-Jays in many areas because of anthropogenic reductions in the fire frequency (Stith et al. 1996, Duncan and Schmalzer 2004, Duncan et al. 2004). Most fires that occur are the result of controlled fires used to reduce dangerous fuels and to manage for species of conservation concern, such as Florida ScrubJays. Scrub occurs on ancient dunes and is dominated by less flammable scrub oaks (Quercus myrtifolia, $Q$. geminata) that are intermixed and adjacent to very flammable flatwoods vegetation, such as palmetto (Serenoa repens), shiny lyonia (Lyonia lucida) and 


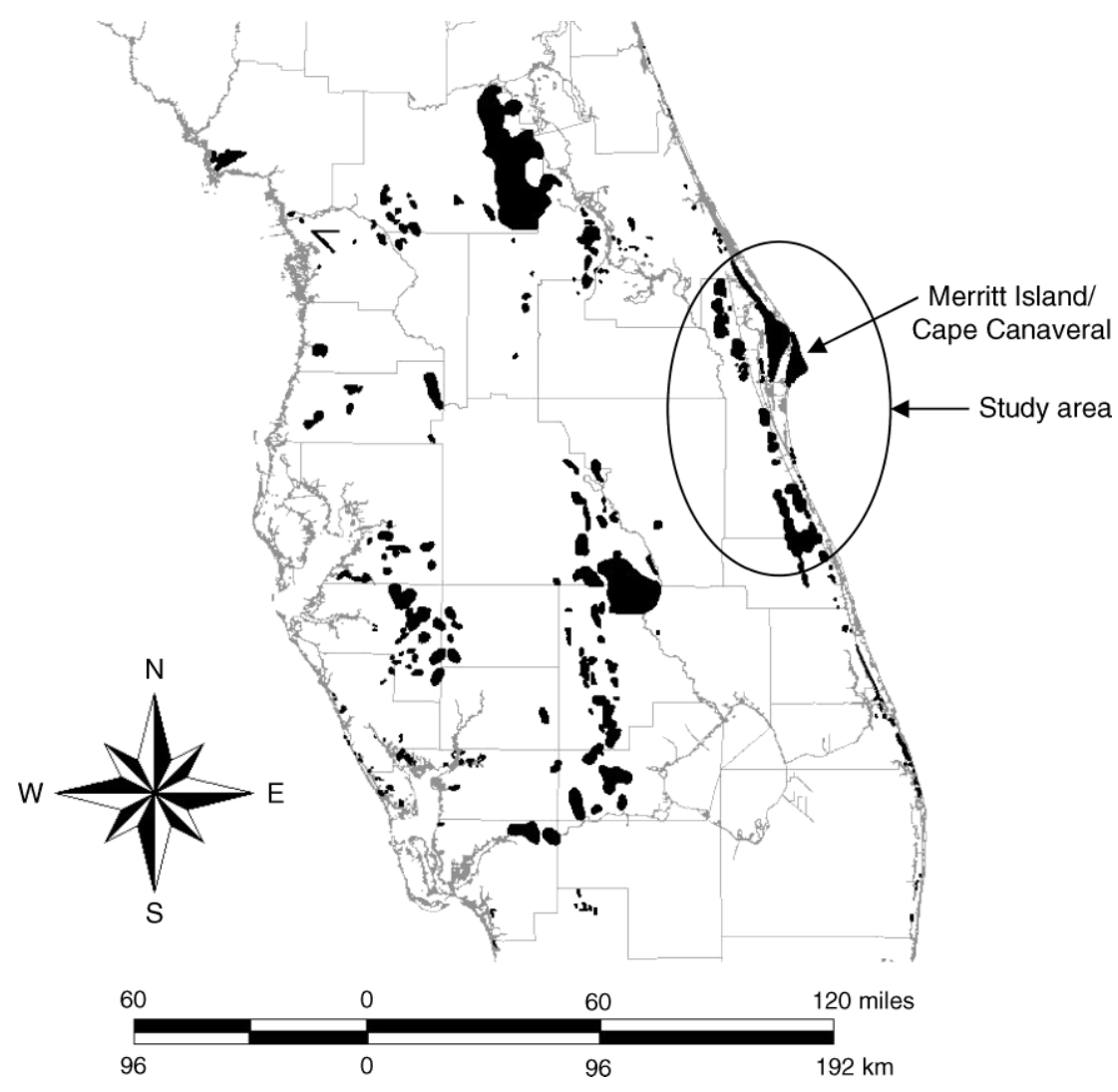

FIG. 1. Map of study region and the range of the Florida Scrub-Jay (Aphelocoma coerulescens), based on Stith et al. (1996). We estimated Florida Scrub-Jay life history parameters within most black areas in the study region except for Merritt Island/Cape Canaveral, where our studies sites represented less than one-quarter of the total area occupied by Florida Scrub-Jays. The gray lines represent Florida county and shoreline boundaries.

wiregrass (Aristida stricta) (Breininger et al. 2002). Recently burned habitat has an open tree canopy of longleaf pine (Pinus palustris), slash pine (P. elliotii), or sand pine ( $P$. clausa). Grasses and shrubs sprout rapidly after fire so that composition changes little in frequently burned areas (Schmalzer et al. 2003). The pines are resilient to most fires, except for sand pines that produce serotinous cones. Fire return intervals in managed areas are 3-15 years for oak scrub and 2-8 years for pine flatwoods (Breininger et al. 2002). Tall scrub burns poorly and often needs mechanical cutting to reduce its extent (Schmalzer and Boyle 1998, Duncan et al. 1999, Schmalzer et al. 2003).

\section{Data collection}

From 1988 to 2005 we attempted to uniquely colorband all individuals within our study areas using a numbered aluminum band and 2-3 color bands. We captured birds using baited Potter traps, drop traps, and mist nets. Florida Scrub-Jays were often curious towards humans and familiar with human handouts because most populations occur near or within humandominated landscapes (Stith et al. 1996, Bowman and Woolfenden 2001). We were unable to capture $\sim 10 \%$ of the individuals and excluded them from survival analyses. We identified breeding status and family composition by performing monthly surveys (Woolfenden and Fitzpatrick 1984, Breininger et al. 2006). Breeders were distinguished by pair bond behaviors; nonbreeders were nearly always young of one or both of the breeders that delayed breeding for at least one nesting season after they hatched. Females were identified by a unique hiccup call. We conducted territory mapping from April through May by observing disputes between families and instigating territory boundary display using playback of territorial calls.

Each year, we classified every Florida Scrub-Jay territory $(n=1719)$ into one of the four territory quality states. The short territory state $(<1.2 \mathrm{~m}$ tall $)$ was identified by territories being burned completely within three years and having open sand visible between individual oak shrubs. The optimal state had an abundance of open sandy areas among medium-height patches of oak scrub (1.2-1.7 $\mathrm{m}$ tall) that were $>0.4$ ha in size. Medium-height patches had interlocking shrub canopies forming a smooth texture on 1.0 -m resolution aerial photography. The tall mix state had short or medium-height scrub patches among patches of tall oaks $(>1.7 \mathrm{~m}$ tall) greater than 0.4 ha in size. Tall oaks produce shadows and tones that create a coarse texture 
on 1.0-m resolution aerial photography (Paine 1981). The tall state lacked short and medium-height oaks and usually lacked open sand, except along man-made clearings. Habitat quality in study areas was also classified within 1450 grid cells using exactly the same habitat quality states as used for the birds themselves. These data were used to model habitat dynamics in order to compare bird territory quality transitions with habitat quality transitions that did not result from bird habitat selection. Each grid cell was 10 ha, which represented average territory size at carrying capacity (Woolfenden and Fitzpatrick 1984). The habitat quality state of these grid cells was classified using $1.0-\mathrm{m}$ resolution digital orthophoto quads available in 1994 , 1999, and 2004 (Breininger et al. 2006, Carter et al. 2006).

\section{Capture-recapture}

General modeling approach.-We used multistate capture-recapture models to estimate survival rates of Florida Scrub-Jays stratified by territory quality state and to test the predictions of our hypotheses. Multistate models use capture-recapture or resighting data from $K$ sampling occasions (Nichols et al. 1994, Nichols and Kendall 1995). The basic Arnason-Schwarz model (Arnason 1972, 1973, Brownie et al. 1993, Schwarz et al. 1993) assumes that state transitions from one sampling occasion to the next represent a first-order Markov process in that the probability of making a specified transition between occasions $i$ and $i+1$ depends only on the state at time $i$. The basic parameters for this model are as follows:

$\phi_{i}^{r s}=$ the probability that an organism alive in state $r$ at time $i$ is alive and in state $s$ at time $i+1$,

$p_{i}^{s}=$ the probability that a marked organism alive in state $s$ at time $i$ is recaptured or resighted on that sampling occasion.

Because $\phi_{i}^{r s}$ reflects the probability of both surviving and making a specified state transition, it is often of interest to compute the following derived parameters (Hestbeck et al. 1991, Brownie et al. 1993, Schwarz et al. 1993):

$S_{i}^{r}=\Sigma \phi_{i}^{r s}=$ the probability that an organism alive in state $r$ at time $i$ survives (and does not permanently emigrate from the study locations) until time $i+1$.

$\psi_{i}^{r s}=\phi_{i}^{r s} / S_{i}^{r}=$ the probability of being in state $s$ at time $i+1$ for organisms that were alive in state $r$ at time $i$ and survived until $i+1$.

If survival between $i$ and $i+1$ depends only on state at time $i$ (and not on state at time $i+1$ ), then the $\psi_{i}^{r s}$ can be viewed as conditional (on survival) state transition probabilities and used to provide inferences about the state transition process. In such cases, it is reasonable to parameterize the multistate models in terms of $S_{i}^{r}$ and $\psi_{i}^{r s}$ :

$$
\phi_{i}^{r s}=S_{i}^{r} \psi_{i}^{r s}
$$

This parameterization permits direct estimation of $S_{i}^{r}$ and $\psi_{i}^{r s}$ and permits tests of hypotheses specific to these separate parameters using constrained models where certain parameters (e.g., time-specific parameters) can be set equal to each other.

We performed multistate mark-recapture analyses to draw inferences about $p, S$, and $\psi$ using Program MARK (version 5.1; White and Burnham 1999).

Florida Scrub-Jay data.-We used resightings data for individual birds from the late May monthly census, which was the end of the nesting season. We began by assessing fit of our most general (global) model, in which all model parameters $(p, \psi$, and $s)$ were modeled as time (year) dependent. We assessed fit of the most general model using the U-CARE software (Choquet et al. 2003, Pradel et al. 2003). The goodness-of-fit test statistic resulted in $\hat{c}<1$, providing no evidence of a need for the overdispersion parameter, $c$, in the model selection process. We then developed reduced-parameter models to reflect different hypotheses about sources of variation in model parameters. The multinomial-logit link function was used to model territory quality transitions as a function of covariates. Model selection was based on a modified version of Akaike's Information Criterion that included corrections for small sample size $\left(\mathrm{AIC}_{\mathrm{c}}\right)$. Model weights were computed to reflect the relative (to members of the model set) appropriateness of each model (Buckland et al. 1997, Burnham and Anderson 2002).

We modeled $p, \psi$, and $S$ in sequence using a priori model sets in order to maintain a manageable set of models (e.g., Franklin et al. 2004). For example, we focused on the modeling of $p$ using a model set in which survival and transition probabilities were modeled very generally. Survival was modeled as a function of habitat $\times \operatorname{sex} \times$ time and transition parameters were modeled as a function of habitat $x$ time, where $\times$ refers to inclusion of interactions. The most parsimonious model(s) for detection probabilities was then used in all subsequent models developed for $\psi$ and $S$. In the model set focusing on $\psi$, survival was again modeled as a function of habitat $\times \operatorname{sex} \times$ time. We focused on survival last, because it was the parameter of most interest. The survival modeling was based on the models for $p$ and $\psi$ that had been selected based on the previous modeling steps. In all models, $\psi$ was set to 0.0 for transitions that never occurred (short to tall, optimal to tall, tall to short, and tall to optimal) to aid in numerical estimation. Modeling for the focal parameters included both additive and interactive covariate models. Models for survival included some that replaced time with "epidemic," which distinguished epidemic years from non-epidemic years. Epidemic years represented rare die-offs in study sites across central Florida and are believed to be years of mosquito-borne arbovirus outbreaks (i.e., 1979, 1997; Woolfenden and Fitzpatrick 1984, Breininger 1999, Garvin et al. 2004).

Habitat data.-We investigated habitat dynamics by estimating habitat transition probabilities for the 10-ha 
TABLE 1. Model selection rankings of detection probability models for Florida Scrub-Jays (Aphelocoma coerulescens) banded and captured along the Atlantic coast of Florida, USA, 1988-2005.

\begin{tabular}{|c|c|c|c|c|c|c|}
\hline \multicolumn{3}{|c|}{ Model } & \multirow[b]{2}{*}{$\Delta \mathrm{AIC}_{\mathrm{c}}$} & \multirow{2}{*}{$\begin{array}{c}\mathrm{AIC}_{\mathrm{c}} \\
\text { weights }\end{array}$} & \multirow[b]{2}{*}{ Deviance } & \multirow{2}{*}{$\begin{array}{c}\text { No. } \\
\text { parameters }\end{array}$} \\
\hline$S$ & $\psi$ & $p$ & & & & \\
\hline$h \times s \times t$ & $h \times t$ & $\mathrm{~h}$ & 0.00 & 0.63 & 2600.21 & 280 \\
\hline $\mathrm{h} \times \mathrm{s} \times \mathrm{t}$ & $h \times t$ & $h+s$ & 1.97 & 0.24 & 2599.81 & 281 \\
\hline $\mathrm{h} \times \mathrm{s} \times \mathrm{t}$ & $h \times t$ & $h+t$ & 4.77 & 0.06 & 2569.24 & 295 \\
\hline $\mathrm{h} \times \mathrm{s} \times \mathrm{t}$ & $h \times t$ & $h \times s$ & 5.36 & 0.04 & 2596.08 & 284 \\
\hline $\mathrm{h} \times \mathrm{s} \times \mathrm{t}$ & $\mathrm{h} \times \mathrm{t}$ & $\mathrm{h}+\mathrm{s}+\mathrm{t}$ & 6.73 & 0.02 & 2568.82 & 296 \\
\hline$h \times s \times t$ & $h \times t$ & $t \times s$ & 8.34 & 0.01 & 2594.30 & 286 \\
\hline $\mathrm{h} \times \mathrm{s} \times \mathrm{t}$ & $\mathrm{h} \times \mathrm{t}$ & - & 28.76 & $<0.01$ & 2636.08 & 277 \\
\hline $\mathrm{h} \times \mathrm{s} \times \mathrm{t}$ & $h \times t$ & $h \times t$ & 29.80 & $<0.01$ & 2533.95 & 320 \\
\hline $\mathrm{h} \times \mathrm{s} \times \mathrm{t}$ & $h \times t$ & $\mathrm{~s}$ & 31.05 & $<0.01$ & 2636.00 & 278 \\
\hline $\mathrm{h} \times \mathrm{s} \times \mathrm{t}$ & $h \times t$ & $\mathrm{t}$ & 31.79 & $<0.01$ & 2603.44 & 292 \\
\hline $\mathrm{h} \times \mathrm{s} \times \mathrm{t}$ & $\mathrm{h} \times \mathrm{t}$ & $\mathrm{s}+\mathrm{t}$ & 34.07 & $<0.01$ & 2603.33 & 293 \\
\hline $\mathrm{h} \times \mathrm{s} \times \mathrm{t}$ & $h \times t$ & $\mathrm{~h} \times \mathrm{s} \times \mathrm{t}$ & 157.70 & $<0.01$ & 2492.76 & 388 \\
\hline
\end{tabular}

Notes: Abbreviations are: $S$, survival; $\psi$, habitat transition probability; $p$, detection probability; $h$, habitat; s, sex; t, time; + , additive; and $\times$, interactions. A dash indicates that the parameter was treated as a constant.

grid cells in study sites. We used capture-recapture software MARK (White and Burnham 1999) as a convenient way to fit Markov models of multistate dynamics to habitat state data with missing years. Specifically, we estimated habitat transition probabilities $\left(\psi_{i}^{r s}\right.$, where $i$ denotes time and $r$ and $s$ denote habitat states) in MARK by fixing detection probabilities to 1.0 for 1994, 1999, 2004 (the years for which habitat classification data existed) and 0.0 for all intervening years, and by fixing "survival" to 1 for all years (all cells remained in the study for the 10 -year period). We constrained annual transition probability parameters to be constant over time $\psi_{i}^{r s}=\psi^{r s}$, in order to estimate a single set of parameters corresponding to the average annual habitat transition probabilities over the entire period. The estimated transition probabilities were used to form a $4 \times 4$ habitat transition matrix. We estimated the asymptotic distribution of habitat states by computing the right eigenvector associated with the dominant eigenvalue of this habitat transition matrix.

Habitat selection metric.-Finally, a matrix was computed to reflect the degree to which bird territory quality transitions reflected passive changes in habitat states within a location vs. active selection by birds of particular habitats and avoidance of others. Habitat quality was ordered from best to worst (optimal, tall mix, tall, short) based on preliminary inferences from earlier studies (e.g., Breininger et al. 2006). Each entry in the matrix is viewed as a bird selection ratio and was computed as: $\hat{\theta}^{r s}=\hat{\psi}_{b}^{r s} / \hat{\psi}_{h}^{r s}$, the ratio of the time-constant transition probability for breeding birds (denoted with subscript $b$ ) to that for habitat (subscript $h$ ). Values of $\hat{\theta}^{r s}$ near 1.0 represent no selection by birds (territory habitat transitions reflected passive habitat change), whereas $\hat{\theta}^{r s}>1$ represents selection of habitat state $s$, and $\hat{\theta}^{r s}<1$ reflects movement away from habitat state $s$. We predicted $\hat{\theta}^{r s}>1$ when the new habitat state $(s)$ is of higher quality than the old habitat state $(r)$, and $\hat{\theta}^{r s}<1$ when the new habitat state is of poorer quality than the old habitat state. The variance of this bird selection ratio was computed as follows (e.g., Mood et al. 1974):

$$
\widehat{\operatorname{var}}\left(\hat{\theta}^{r s}\right)=\left(\hat{\theta}^{r s}\right)^{2}\left[\frac{\widehat{\operatorname{var}}\left(\hat{\psi}_{b}^{r s}\right)}{\left(\hat{\psi}_{b}^{r s}\right)^{2}}+\frac{\widehat{\operatorname{var}}\left(\hat{\psi}_{h}^{r s}\right)}{\left(\hat{\psi}_{h}^{r s}\right)^{2}}\right] .
$$

Approximate 95\% confidence intervals were computed for the bird selection ratios as

$$
\begin{gathered}
\hat{\theta}^{r s} \pm 1.96 \sqrt{\widehat{\operatorname{var}}\left(\hat{\theta}^{r s}\right)} . \\
\text { Results } \\
\text { Model selection }
\end{gathered}
$$

\section{Model selection}

The capture histories involved 1214 breeding Florida Scrub-Jays. The most parsimonious model for detection probability was specific to habitat but did not vary by time or sex (Table 1). Transition probabilities were best described as a function of habitat + time, where "+" refers to an additive model without interactions (Table 2). The best survival model was habitat + time specific (Table 3). Models with habitat and time interactions had little support, and neither did models that substituted epidemics for annual variation.

\section{Parameter estimates}

Detection probabilities did not exactly match a priori predictions because the short state did not have the highest detection probabilities (Fig. 2). As predicted, the estimated $\beta$ parameters reflecting sex effects on detection probability had little influence compared to those associated with habitat under the less supported model $S$ (habitat $+\operatorname{sex}+$ time) $p$ (habitat $+\operatorname{sex}) \psi$ (habitat + time).

Most states remained the same between years for birds and grid cells (Table 4). The greatest annual 
TABLE 2. Model selection rankings of transition probability models for Florida Scrub-Jays banded and captured along Florida's Atlantic coast, 1988-2005.

\begin{tabular}{|c|c|c|c|c|c|c|}
\hline \multicolumn{3}{|c|}{ Model } & \multirow[b]{2}{*}{$\Delta \mathrm{AIC}_{\mathrm{c}}$} & \multirow{2}{*}{$\begin{array}{c}\mathrm{AIC}_{\mathrm{c}} \\
\text { weights }\end{array}$} & \multirow[b]{2}{*}{ Deviance } & \multirow{2}{*}{$\begin{array}{c}\text { No. } \\
\text { parameters }\end{array}$} \\
\hline$S$ & $\psi$ & $p$ & & & & \\
\hline $\mathrm{h} \times \mathrm{s} \times \mathrm{t}$ & $h+t$ & $\mathrm{~h}$ & 0.00 & 1.00 & 2737.14 & 212 \\
\hline$h \times s \times t$ & $h \times t$ & $\mathrm{~h}$ & 92.71 & $<0.01$ & 2600.21 & 280 \\
\hline $\mathrm{h} \times \mathrm{s} \times \mathrm{t}$ & $\mathrm{h}$ & $\mathrm{h}$ & 118.85 & $<0.01$ & 2998.59 & 148 \\
\hline
\end{tabular}

Note: See Table 1 for abbreviations.

variation in transition probabilities for birds occurred within short and optimal states. Transitions from optimal to short were high during years of extensive wildfires or prescribed burns that killed nearly all above ground shrubs. The least annual variation occurred among tall mix transitions because territories in that state usually stayed in that state. Tall states transitioned to tall mix most often when restoration activities cut much tall scrub while keeping some tall scrub intact to serve as cover for resident Florida Scrub-Jays (Schmalzer and Boyle 1998).

The relative percentages of grid cells in the short, optimal, tall mix, and tall states in 2004 were 12, 18, 50, and 20 , respectively. The asymptotic distribution of habitat states among grid cells was $13 \%, 27 \%, 43 \%$, and $17 \%$ based on average transition probabilities. Quantifying how fire frequency, mechanical cutting, and other covariates influence transitions between habitat states of grid cells is the subject of an ongoing study. Although the asymptotic distribution of habitat states is particular to the studied set of years and their specific fire frequencies and management activities, it is important that the percentage of optimal territories was low and likely to remain low.
Differences between time-constant transition probabilities among habitat states for bird territories and grid cells were usually small (Table 4), yielding habitat selection metrics near 1.0. This general result is consistent with our basic prediction that most changes in territory state occurred because of habitat change rather than bird movement. Habitat selection metrics that differed from 1.0 were consistent with those expected based on our predictions about habitat preference or avoidance for only seven of the 12 transitions. The CIs for most habitat selection metrics overlapped 1.0, providing little evidence for habitat preference or avoidance and instead supporting the basic conclusion that most change in territory quality was associated with habitat dynamics rather than bird movement. The only two habitat selection metrics that did not overlap 1.0 (corresponding to the transitions from tall mix to optimal, and tall to tall mix) were both $>1.0$ as predicted.

A model that included sex $(S$ (habitat + time + sex $))$ had some support, but differences in point estimates of survival between sexes were nearly identical and differences were smaller than standard errors. The model that assumed annual time variation had much

TABLE 3. Final model selection table for survival of Florida Scrub-Jays banded and captured along Florida's Atlantic coast 1988-2005.

\begin{tabular}{lcccccc}
\hline \hline \multicolumn{1}{c}{ Model } & & & & & \\
\multicolumn{1}{c}{$S$} & $\psi$ & $p$ & $\Delta \mathrm{AIC}_{\mathrm{c}}$ & $\begin{array}{c}\mathrm{AIC}_{\mathrm{c}} \\
\text { weights }\end{array}$ & Deviance & $\begin{array}{c}\text { No. } \\
\text { parameters }\end{array}$ \\
\hline $\mathrm{h}+\mathrm{t}$ & $\mathrm{h}+\mathrm{t}$ & $\mathrm{h}$ & 0.00 & 0.71 & 2862.96 & 96 \\
$\mathrm{~h}+\mathrm{s}+\mathrm{t}$ & $\mathrm{h}+\mathrm{t}$ & $\mathrm{h}$ & 1.81 & 0.29 & 2862.65 & 97 \\
$\mathrm{~h} \times \mathrm{e}$ & $\mathrm{h}+\mathrm{t}$ & $\mathrm{h}$ & 10.31 & 0.00 & 2898.59 & 84 \\
$\mathrm{~h}+\mathrm{e}$ & $\mathrm{h}+\mathrm{t}$ & $\mathrm{h}$ & 14.13 & 0.00 & 2908.71 & 81 \\
$\mathrm{~h}+\mathrm{s}+\mathrm{e}$ & $\mathrm{h}+\mathrm{t}$ & $\mathrm{h}$ & 15.89 & 0.00 & 2908.37 & 82 \\
$\mathrm{t}$ & $\mathrm{h}+\mathrm{t}$ & $\mathrm{h}$ & 15.97 & 0.00 & 2885.28 & 93 \\
$\mathrm{~s}+\mathrm{t}$ & $\mathrm{h}+\mathrm{t}$ & $\mathrm{h}$ & 17.78 & 0.00 & 2884.97 & 94 \\
$\mathrm{~h} \times \mathrm{s} \times \mathrm{e}$ & $\mathrm{h}+\mathrm{t}$ & $\mathrm{h}$ & 17.97 & 0.00 & 2895.72 & 89 \\
$\mathrm{~h}$ & $\mathrm{~h}+\mathrm{t}$ & $\mathrm{h}$ & 25.53 & 0.00 & 2922.21 & 80 \\
$\mathrm{~h}+\mathrm{s}$ & $\mathrm{h}+\mathrm{t}$ & $\mathrm{h}$ & 31.58 & 0.00 & 2921.96 & 83 \\
$\mathrm{~h} \times \mathrm{s}$ & $\mathrm{h}+\mathrm{t}$ & $\mathrm{h}$ & 32.19 & 0.00 & 2920.47 & 84 \\
$\mathrm{e}$ & $\mathrm{h}+\mathrm{t}$ & $\mathrm{h}$ & 33.06 & 0.00 & 2933.93 & 78 \\
$\mathrm{e}+\mathrm{s}$ & $\mathrm{h}+\mathrm{t}$ & $\mathrm{h}$ & 34.84 & 0.00 & 2933.61 & 79 \\
$\mathrm{t} \times \mathrm{s}$ & $\mathrm{h}+\mathrm{t}$ & $\mathrm{h}$ & 35.93 & 0.00 & 2869.13 & 110 \\
$\mathrm{e} \times \mathrm{s}$ & $\mathrm{h}+\mathrm{t}$ & $\mathrm{h}$ & 36.39 & 0.00 & 2933.07 & 80 \\
$-\mathrm{s}$ & $\mathrm{h}+\mathrm{t}$ & $\mathrm{h}$ & 44.35 & 0.00 & 2947.31 & 77 \\
$\mathrm{~h} \times \mathrm{t}$ & $\mathrm{h}+\mathrm{t}$ & $\mathrm{h}$ & 46.21 & 0.00 & 2947.07 & 78 \\
$\mathrm{~h} \times \mathrm{s} \times \mathrm{t}$ & $\mathrm{h}+\mathrm{t}$ & $\mathrm{h}$ & 46.93 & 0.00 & 2806.78 & 144 \\
\hline
\end{tabular}

Notes: See Table 1 for abbreviations; in addition, "e" indicates "epidemic." A dash indicates that the parameter was treated as a constant. 


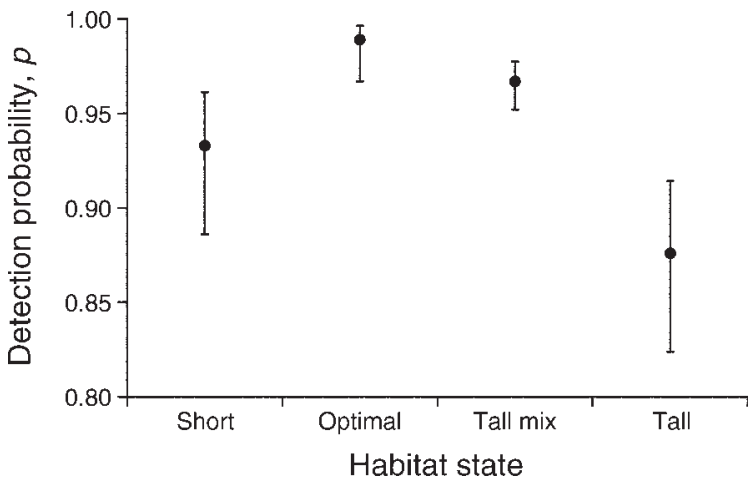

FIG. 2. Real parameter estimates and 95\% CI for detection probabilities under the best model in different habitat states.

greater support than models that substituted epidemics for time, though survival was lowest during the epidemic in 1997 (Appendix). We used a time-constant survival model to provide a useful summary of habitat-specific survival estimates; annual survival estimates (mean \pm SE) were $0.71 \pm 0.02,0.82 \pm 0.01,0.75 \pm 0.01$, and 0.73 \pm 0.02 , respectively, for short, optimal, tall mix, and tall, and were consistent with a priori predictions.

\section{DisCUSSION}

\section{Detection probabilities}

Florida Scrub-Jay detection probabilities approached 1.0 for tall mix, which was the most abundant territory quality state, and optimal, which was the desired state for population recovery. The tall state had the lowest detection probability, as expected, because this was the densest habitat having the lowest visibility for the investigators. Florida Scrub-Jays have an effective sentinel system for detection of predators in the optimal state that is less effective in the tall state resulting in wary behavior (McGowan and Woolfenden 1989).
Detection probabilities were intermediate for the short state, which had sparse cover. This unexpected result might have been because jays were wary in the short state because they had little cover to escape predators, such as Cooper's Hawks. It may also be that territorial behavior is a function of territory quality, being most pronounced (and leading to higher detection probability) for birds in the optimal state.

\section{Transition probabilities}

Bird and habitat transition probabilities were similar, indicating that most bird territory quality transitions resulted from habitat dynamics rather than bird movement. Florida Scrub-Jays had limited opportunity to adjust their territory boundaries to select better habitat conditions. For example, Florida Scrub-Jays residing in optimal territories often transitioned to short because of extensive fires. In extensively burned areas it was difficult or impossible to incorporate mediumheight scrub into their territories, because such scrub did not exist or was defended by other families. Transition from optimal to tall mix often occurred in landscapes where fires didn't occur often enough, resulting in territory quality transitions occurring via succession for these sedentary breeders. Many tall mixto-tall transitions occurred in habitat fragments outside managed areas where scrub remained unburned and where vegetation grew taller.

Bird and habitat transitions between short and optimal occurred naturally as vegetation recovered from fires (Breininger and Oddy 2004). Tall and tall mix territories were likely to remain in their same state because scrub $>1.7 \mathrm{~m}$ tall is difficult to ignite and often needs mechanical cutting or hot fires to return it to a fire maintained community (Schmalzer and Boyle 1998, Duncan et al. 1999). The abundance of tall scrub and its resistance to burning explain why most territories are suboptimal and likely to remain in that condition.

TABLE 4. Comparison of bird territory quality and habitat transition probabilities (with SE in parentheses for $\psi$, and $95 \%$ CI for habitat selection metric).

\begin{tabular}{lcccc}
\hline \hline \multicolumn{1}{c}{ Transition } & Bird $\psi$ & Habitat $\psi$ & $\begin{array}{c}\text { Bird } \psi / \text { habitat } \psi \\
\text { selection metric }\end{array}$ & $\begin{array}{c}\text { Expected } \\
\text { habitat } \\
\text { selection }\end{array}$ \\
\hline Short to short & $0.740(0.024)$ & $0.798(0.018)$ & $0.94(0.55-1.33)$ & $<1$ \\
Short to optimal & $0.234(0.023)$ & $0.168(0.017)$ & $1.40(0.00-3.39)$ & $>1$ \\
Short to tall mix & $0.021(0.008)$ & $0.044(0.089)$ & $0.47(0.00-1.94)$ & $>1$ \\
Optimal to short & $0.130(0.013)$ & $0.044(0.008)$ & $2.97(0.38-5.56)$ & $<1$ \\
Optimal to optimal & $0.785(0.016)$ & $0.932(0.008)$ & $0.84(0.00-2.13)$ & $>1$ \\
Optimal to tall mix & $0.084(0.011)$ & $0.025(0.004)$ & $3.45(0.97-5.93)$ & $<1$ \\
Tall mix to short & $0.025(0.004)$ & $0.038(0.003)$ & $0.67(0.00-2.14)$ & $<1$ \\
Tall mix to optimal & $0.040(0.005)$ & $0.007(0.002)$ & $5.46(2.31-8.61)$ & $>1$ \\
Tall mix to tall mix & $0.919(0.007)$ & $0.947(0.002)$ & $0.97(0.00-2.19)$ & $<1$ \\
Tall mix to tall & $0.016(0.003)$ & $0.008(0.001)$ & $1.93(0.21-3.65)$ & $<1$ \\
Tall to tall mix & $0.109(0.017)$ & $0.036(0.003)$ & $3.02(1.35-4.69)$ & $>1$ \\
Tall to tall & $0.891(0.017)$ & $0.960(0.003)$ & $0.93(0.12-1.74)$ & $<1$ \\
\hline
\end{tabular}

Notes: Habitat transition probabilities were mapped independently of bird territory boundaries within the study sites using 10-ha grid cells. Bird transitions are time-constant estimates from multistate capture-recapture models. Habitat transitions are estimated from a time-constant habitat transition model. 


\section{Survival}

Separating the epidemic year from other years did not result in a better survival model, because there was substantial annual survival variation across years when range wide epidemics were not observed. Frequent, but small, disease outbreaks might cause variation in Florida Scrub-Jay survival. The presence of positive arbovirus exposure in the blood of sentinel chickens frequently has a patchy temporal and spatial distribution (Brevard County Health Department, unpublished data). Other factors causing variation in survival might result from fluctuations in predation. Breeder disappearances (presumed mortality) are highest during months of high snake activity and accipiter migration and are rare during periods of lowest food availability (Woolfenden and Fitzpatrick 1984, Breininger et al. 1996). The differences in point estimates in male and female breeder survival were small relative to standard errors of the estimates. The direction of the differences was consistent with an explanation of female susceptibility to mortality while incubating or brooding, particularly from snakes (Carter et al. 2007).

Birds in the optimal territory quality state had the greatest survival, as expected. This is an important result, as strong inferences about habitat specificity of survival are rare for mobile vertebrates, despite the widespread belief in the importance of habitat to fitness components. The survival differences we observed between optimal and other territory quality states would be very influential when applied to Florida Scrub-Jay population models (Root 1998, Breininger et al. 1999). For relatively long-lived species, survival generally is one of the most important factors determining population growth rates and fitness (e.g., Gaillard et al. 1998, Pfister 1998, Sandercock 2006). One reason that habitatspecific survival inferences are seldom published is the difficulty in distinguishing the effects of detection probability, movement, and survival on raw detection history data (Conroy et al. 1996). We believe our estimates of apparent survival are nearly identical to true survival because Florida Scrub-Jays nearly always remain in the same territory for life once they become breeders.

Most Florida Scrub-Jay populations are likely to continue their decline because of poor habitat-specific survival, relative to fecundity needed to sustain populations (Breininger et al. 2006), even though the proportion of optimal habitat has been increasing slightly in recent years. These improvements could be reversed if management efforts were curtailed; the extirpation of Florida Scrub-Jays in unburned habitat fragments has long been established (Woolfenden and Fitzpatrick 1984, Stith et al. 1996). Differences observed in survival between short and tall mix have management implications. In contrast to slower population declines observed for populations dominated by tall mix states, we often observe steep population declines in Florida Scrub-Jay populations subjected to extensive fire (e.g.,
Breininger and Carter 2003, Breininger and Oddy 2004, Breininger et al. 2006). These declines last a few years before the population recovers when the populations are large and widely distributed, but recovery frequently does not occur in small, fragmented populations (D. R. Breininger, J. D. Nichols, G. M. Carter, and D. M. Oddy, unpublished data).

Occasional extensive fire might be beneficial because it can eliminate tall scrub or keep tall scrub from accumulating (Breininger et al. 2002); the decision to attempt extensive fire might be made depending on habitat and population state. Results of this study present the manager with an interesting, yet not uncommon, problem. For Florida Scrub-Jays and other species that prefer intermediate transitional states, difficulties arise because succession eventually moves habitat away from preferred states, and the primary management action and cause of disturbance (fire) can move the habitat into a different suboptimal state. Wise management in such situations represents a nontrivial problem in dynamic optimization (Nichols and Williams 2006; F. A. Johnson, D. R. Breininger, B. W. Duncan, B. K. Williams, and M. C. Runge, unpublished manuscript).

\section{AcKnowledgments}

This study was funded by NASA, U.S. Fish and Wildlife Service, Florida Department of Environmental Protection, Florida Fire Science Team, Brevard Zoo, Brevard Nature Alliance, and Friends of Scrub. We thank J. Hines, M. Legare, J. Elseroad, B. Dunning, F. Johnson, C. Hall, R. Noss, V. Larson, R. Bolt, M. Barkaszi, S. Brisbin, B. Summerfield, B. Toland, R. Hight, Merritt Island National Wildlife Refuge, Brevard County Environmentally Endangered Lands Program, and the St. Johns River Water Management District for their help in bringing this study to fruition as a published paper.

\section{Literature Cited}

Amarasekare, P., and H. Possingham. 2001. Patch dynamics and metapopulation theory: the case of successional species. Journal of Theoretical Biology 209:333-344.

Anders, A. D., and M. R. Marshall. 2005. Increasing the accuracy of productivity and survival estimates in assessing landbird status. Conservation Biology 19:66-74.

Armstrong, D. P. 2004. Integrating the metapopulation and habitat paradigms for understanding broad-scale declines of species. Conservation Biology 19:1402-1410.

Arnason, A. N. 1972. Parameter estimates from mark recapture experiments on two populations subject to migration and death. Researches on Population Ecology 13:97-113.

Arnason, A. N. 1973. The estimation of population size, migration rates, and survival in a stratified population. Researches in Population Ecology 15:1-8.

Bowman, R., and G. E. Woolfenden. 2001. Nest success and the timing of nest failure of Florida Scrub-Jays in suburban and wildland habitats. Pages 383-402 in J. M. Marzluff, R. Bowman, and R. E. Donnelly, editors. Avian conservation and ecology in an urbanizing world. Kluwer Academic Publishers, New York, New York, USA.

Breininger, D. R. 1999. Florida Scrub-Jay demography and dispersal in a fragmented landscape. Auk 116:520-527.

Breininger, D. R., M. A. Burgman, and B. M. Stith. 1999. Influence of habitat, catastrophes, and population size on extinction risk on Florida Scrub-Jay populations. Wildlife Society Bulletin 27:810-822. 
Breininger, D. R., and G. M. Carter. 2003. Territory quality transitions and source-sink dynamics in a Florida Scrub-Jay population. Ecological Applications 13:516-529.

Breininger, D. R., B. W. Duncan, and N. J. Dominy. 2002. Relationships between fire frequency and vegetation type in pine flatwoods of east-central Florida, USA. Natural Areas Journal 22:186-193.

Breininger, D. R., V. L. Larson, D. M. Oddy, R. B. Smith, and M. J. Barkaszi. 1996. Florida Scrub-Jay demography in different landscapes. Auk 112:617-625.

Breininger, D. R., and D. M. Oddy. 2004. Do habitat potential, population density, and fires influence Florida Scrub-Jay source-sink dynamics? Ecological Applications 14:10791089.

Breininger, D. R., B. Toland, D. M. Oddy, and M. L. Legare. 2006. Landcover characterizations and Florida Scrub-Jay (Aphelocoma coerulescens) population dynamics. Biological Conservation 127:169-181.

Brownie, C., J. E. Hines, J. D. Nichols, K. H. Pollock, and J. B. Hestbeck. 1993. Capture-recapture studies for multiple strata including non-Markovian transitions. Biometrics 49:11731187.

Buckland, S. T., K. P. Burnham, and N. H. Augustin. 1997. Model selection: an integral part of inference. Biometrics 53: 603-618.

Burnham, K. P., and D. R. Anderson. 2002. Model selection and multimodel inference: a practical information-theoretic approach. Springer-Verlag, New York, New York, USA.

Carter, G. M., M. L. Legare, D. R. Breininger, and D. M. Oddy. 2007. Nocturnal nest predation: a potential obstacle to recovery of a Florida Scrub-Jay population. Journal of Field Ornithology 78:390-394.

Carter, G. M., E. D. Stolen, and D. R. Breininger. 2006. A rapid approach to modeling species-habitat relationships. Biological Conservation 127:237-244.

Choquet, R., A. M. Reboulet, R. Pradel, O. Gimenez, and J. D. Lebreton. 2003. User's manual for U-CARE. Mimeographed document, CEFE/CNRS, Montpellier, France. 〈http://ftp. cefe.cnrs.fr/biom/Soft-CR/Last_Update/

Conroy, M. J. 1993. Testing hypotheses about the relationship of habitat to animal survivorship. Pages 331-342 in J. D. Lebreton and P. M. North, editors. Marked individuals in the study of bird population. Birkhauser-Verlag, Basel, Switzerland.

Conroy, M. J., J. E. Anderson, and S. L. Rathbun. 1996. Statistical inference on patch-specific survival and movement rates from marked animals. Environmental and Ecological Statistics 3:9-116.

Diffendorfer, J. E. 1998. Testing models of source-sink dynamics and balanced dispersal. Oikos 81:417-433.

Duncan, B. W., S. Boyle, D. R. Breininger, and P. A. Schmalzer. 1999. Coupling past management practice and historical landscape change on John F. Kennedy Space Center. Landscape Ecology 14:291-309.

Duncan, B. W., V. L. Larson, and P. A. Schmalzer. 2004. Historic and recent landscape change in the North Indian River Lagoon watershed, Florida. Natural Areas Journal 24: 198-215.

Duncan, B. W., and P. A. Schmalzer. 2004. Anthropogenic influences on potential fire spread in a pyrogenic ecosystem of Florida. Landscape Ecology 19:153-165.

Ellner, S. P., and G. Fussmann. 2003. Effects of successional dynamics on metapopulation persistence. Ecology 84:882889.

Franklin, A. B., et al. 2004. Population dynamics of the California Spotted Owl: a meta-analysis. American Ornithologists' Union Monograph, Number 54. American Ornithologists' Union, Washington, D.C., USA.

Gaillard, J. M., M. Festa-Bianchet, and N. G. Yoccoz. 1998. Population dynamics of large herbivores: variable recruit- ment with constant adult survival. Trends in Ecology and Evolution 13:58-62.

Garvin, M. C., K. A. Travin, L. M. Stark, G. E. Woolfenden, J. W. Fitzpatrick, and J. F. Day. 2004. Arboviral infection on two species of wild jays (Aves: Corvidae): evidence for population impacts. Journal of Medical Entomology 41:215-225.

Hestbeck, J. B., J. D. Nichols, and R. A. Malecki. 1991. Estimates of movement and site fidelity using mark-resight data of wintering Canada Geese. Ecology 72:523-533.

MacKenzie, D. L., J. D. Nichols, J. A. Royle, K. H. Pollock, L. L. Bailey, and J. E. Hines. 2006. Occupancy estimation and modeling: inferring patterns and dynamics of species occurrence. Elsevier, Burlington, Massachusetts, USA.

McGowan, K. J., and G. E. Woolfenden. 1989. A sentinel system in the Florida Scrub-Jay. Animal Behavior 37:1000-1006.

Mood, A. M., F. A. Graybill, and D. C. Boes. 1974. Introduction to the theory of statistics. Third edition. McGraw-Hill, New York, New York, USA.

Mumme, R. L., S. J. Schoech, G. E. Woolfenden, and J. W. Fitzpatrick. 2000. Life and death in the fast lane: demographic consequences of road mortality in the Florida ScrubJays? Conservation Biology 14:501-512.

Nichols, J. D., J. E. Hines, K. H. Pollock, R. L. Hinz, and W. A. Link. 1994. Estimating breeding proportions and testing hypotheses about costs of reproduction with capturerecapture data. Ecology 75:2052-2065.

Nichols, J. D., and W. L. Kendall. 1995. The use of multi-state capture-recapture models to address questions in evolutionary ecology. Journal of Applied Statistics 22:835-846.

Nichols, J. D., and B. K. Williams. 2006. Monitoring for conservation. Trends in Ecology and Evolution 21:669-673.

Paine, D. P. 1981. Aerial photography and image interpretation for resource management. John Wiley and Sons, New York, New York, USA.

Pfister, C. A. 1998. Patterns of variance in stage-structured populations: evolutionary predictions and ecological implications. Proceedings National Academy Sciences 95:213-218.

Pradel, R., C. M. A. Wintrebert, and O. Gimenez. 2003. A proposal for a goodness-of-fit test to the Arnason-Schwarz multisite capture-recapture model. Biometrics 59:43-53.

Pulliam, H. R. 1988. Sources, sinks, and population regulation. American Naturalist 132:652-661.

Root, K. V. 1998. The effects of habitat quality, connectivity, and catastrophes on a threatened species. Ecological Applications 8:854-865.

Sandercock, B. K. 2006. Estimation of demographic parameters from live-encounter data: a summary review. Journal of Wildlife Management 70:1504-1520.

Schmalzer, P. A., and S. R. Boyle. 1998. Restoring longunburned oak-mesic flatwoods requires mechanical cutting and prescribed burning. Restoration and Management Notes 16:96-97.

Schmalzer, P. A., T. E. Foster, and F. W. Adrian. 2003. Responses of long-unburned scrub on the Merritt Island/ Cape Canaveral barrier island complex to cutting and burning. In Proceedings of the Second International Wildland Fire Ecology and Fire Management Congress, American Meteorological Society. 〈http://ams.confex.com/ams/ FIRE2003/techprogram/paper_65188.htm $\rangle$

Schwarz, C. J., J. Schweigert, and A. N. Arnason. 1993. Using tag-recovery data to estimate migration rates. Biometrics 49: 177-194.

Stith, B. M., J. W. Fitzpatrick, G. E. Woolfenden, and B. Pranty. 1996. Classification and conservation of metapopulations: a case study of the Florida Scrub-Jay. Pages 187-216 in D. R. McCullough, editor. Metapopulations and wildlife conservation. Island Press, Covelo, California, USA.

Van Horne, B. 1983. Density as a misleading indicator of habitat quality. Journal of Wildlife Management 47:813-901.

White, G. C., and K. P. Burnham. 1999. Program MARK for survival estimation. Bird Study 46(Supplement):S120-S139. 
Williams, B. K., J. D. Nichols, and M. J. Conroy. 2002 Analysis and management of animal populations. Academic Press, San Diego, California, USA.
Woolfenden, G. E., and J. W. Fitzpatrick. 1984. The Florida Scrub-Jay: demography of a cooperative-breeding bird. Princeton University Press, Princeton, New Jersey, USA.

\section{APPENDIX}

A table showing the results of annual breeder survival for short, optimal, tall mix, and tall territory quality categories (Ecological Archives E090-226-A1). 